\title{
Pathogenesis of Pterygium
}

\author{
JOHN C. HILL and RICHARD MASKE \\ Cape Town
}

\begin{abstract}
Summary
This paper reviews the histological and epidemiological characteristics of pterygium which suggest that chronic exposure to ultraviolet radiation plays an important role in the pathogenesis of this disorder. However, there is conflicting evidence indicating that chronic inflammation from other causes can induce the disease. The results of two epidemiological surveys undertaken in Southern Africa show that pterygium is not closely linked to other chronic actinic disorders such as pinguecula and climatic droplet keratopathy. Pterygia differ from these disorders by their vascularity which is probably induced by chronic inflammation. On histological examination, we found that excised pterygia contained a lymphocytic infiltration consisting predominantly of $T$ cells. In the pathogenesis of pterygium we believe that chronic irritation (from whatever cause) produces a chronic inflammatory cell infiltration with resultant inflammatory oedema, attempt at repair and cell induced angiogenesis. These processes, together with actinic damage, are responsible for the fibrovascular reaction so characteristic of a growing pterygium.
\end{abstract}

Pterygium has been defined by Duke-Elder as a triangular shaped degenerative and hyperplastic process, occurring medially and laterally in the palpebral aperture, in which the bulbar conjunctiva encroaches onto the cornea.' There is still much controversy concerning the aetiology and pathogenesis of pterygium. This paper reviews some of the important pathological and epidemiological features and presents a possible mechanism in the pathogenesis of pterygium.

\section{Histological Features}

On light microscopy pterygia exhibit a zone of varying thickness immediately beneath the bulbar conjunctival and limbal epithelium in which there are accumulations of amorphous, eosinophilic, hyalinised or granular-appearing material resembling degenerated collagen interspersed with coiled or fragmented fibres resembling abnormal elastic tissue. ${ }^{2}$ Often the stromal fibrocytes are increased in number as if proliferating in response to injury. In addition, minor aggregates of a proteinaceous substance, acid mucopolysaccharide, and calcific concretions are seen, especially in older lesions. ${ }^{2}$ Originally the accumulated stromal material was thought to be elastic tissue because it stained with elastic tissue stains. However, this has been disputed as the tissue is resistant to the nonproteolytic enzyme elastase $;^{3}$ hence the terms elastoid and elastotic degeneration were invoked to describe the presumed origin of this material from degenerating collagen. The overlying epithelium may be normal, atrophic or hyperplastic.

From ultrastructural studies, Hogan and Alvarado $^{4}$ concluded that the elastoid 
material is formed from four sources: degenerating collagen, pre-existing elastic fibres, abnormal fibroblast activity, and abnormal ground substance. The inflammation commonly found in pterygia and pingueculae was thought to be due to the degenerative changes in their components, akin to the inflammation that occurs in bone sequestra as a result of collagen necrosis. Austin. Jakobiec, and Iwamoto $^{5}$ also found evidence of collagen degeneration, but only in a thin zone of hyalinisation immediately under the epithelium. Beneath this zone the collections of eosinophilic granular material were found to be composed of excessive numbers of microfibrils (an elastic fibre precursor): numerous fibroblasts were found within this material. The elastotic fibres of light microscopy were found to represent an abnormal maturational phase of elastic fibre production. They concluded that a large component of pingueculae and pterygia is the result of newly synthesised elastic fibre precursors and abnormal maturational forms of elastic fibres (elastodysplasia) that undergo secondary degeneration (elastodystrophy), these structures were presumed to be elaborated by actinically damaged fibroblasts of the substantia propia.

The histological features described are similar to those found in pingueculae and are almost identical to those found in the dermis of sun-exposed skin. ${ }^{2.6}$ Actinic elastosis and chronic radiodermatitis are thought to arise from an abnormal elastogenesis secondary to fibroblastic activation by UV radiation, a similar aetiology has been suggested for pinguecula. ${ }^{6}$ These facts strongly suggest that pterygia and pingueculae are causally related to prolonged actinic damage.

\section{Heredity}

Although heredity is reported to play a role in pterygium it is not crucial. The inheritance is dominant with a low penetrance, but it would appear that the actual lesion is not transmitted but rather the tendency of the eye to react in this way to environment stimuli. ${ }^{1.7}$

\section{Geographic Epidemiology}

One of the most striking features of pterygium is its geographical distribution. Cameron ${ }^{8}$ considered the world distribution of this con- dition and found that countries that are hot, dry, and dusty had a higher prevalence of pterygium. But there were other areas that, although hot, were neither dry nor dusty and yet also had a high prevalence of pterygium. The common factor appeared to be latitude, the disorder occuring mostly between the latitudes of $37^{\circ}$ north and south of the equator. Ultraviolet irradiation, which varies with latitude, was thought by Cameron to be an important factor in the aetiology of pterygium: ${ }^{8}$ this hypothesis has been supported by other workers. ${ }^{9-11}$ Cameron postulated that ultraviolet light damages Bowman's membrane and causes a thickening and hyperplasia in the subconjunctival connective tissue. $^{8}$ The incidence of pterygia also depends on the amount of exposure to the climatic conditions. It is therefore commoner in outdoor workers and in males..$^{7.9 .12}$ Taylor in a study of Australian Aborigines ${ }^{9}$ also found a weak association between annual maximum temperature and pterygium, and a trend for this disorder to be associated with higher evaporation rates although a clear relationship did not exist between pterygia and humidity.

\section{Association With Other Diseases}

There is therefore strong evidence, both from environmental studies and from the histological studies showing similarities with actinic damaged skin, to link ultra-violet irradiation with pinguecula and pterygium formation. But are these last two disorders linked only by the same causative factor or are they different stages in the same disease? A pinguecula has often been said to be a precursor of a pterygium and a factor in its aetiology, ${ }^{13}$ a view that has been supported ${ }^{14.15}$ and disputed. ${ }^{16-18}$ Despite the facts that a pinguecula can become incorporated into a pterygium, both have somewhat similar histological features and there is a strong positive but not absolute correlation with regard to age, sex and habits of work between the two disorders: there is little evidence that one leads to the other. ${ }^{8}$ It is probable that pterygia and pingueculae represent kindred reactions to similar stimuli. ${ }^{1}$ This view is supported by a study of pterygium in welders ${ }^{19}$ in which a positive correlation was found between UV 
light and pterygium but there was no difference in the incidence of pinguecula between welders and controls. Pingueculae tend to be larger and more prevalent in the older people. ${ }^{18}$ Pterygia that occur in the younger population, especially the surfing fraternity, are not usually associated with pingueculae.

Ultraviolet light may not be the only environmental factor associated with pterygia, especially since elastotic degeneration is reportedly uncommon in pterygium in India. ${ }^{20}$ Moreover, a survey of ocular disease among Punjabi Indians who emigrated to British Columbia, Canada ${ }^{21}$ (an area with less solar irradiation than India) suggests that sawmill workers may be prone to pterygia. Punjabi Indian workers in sawmills (an indoor occupation) in both British Columbia and New Delhi were found to have a higher incidence of pterygia than Punjabi farmers (an outdoor occupation) in India. Similar findings have been reported amongst sawmill workers in Taiwan and Thailand. ${ }^{21}$ These findings suggest that other forms of chronic irritation may play a role in the aetiology of pterygium.

Racial differences in the incidence of pterygia, which may reflect a genetic predisposition, occur in certain geographic areas. There is a low incidence amongst Japanese, ${ }^{18}$ but a high incidence amongst certain groups on Aruba, an island off the coast of Venezuela. ${ }^{11}$ In Canada pterygia are more common in Indian sawmill workers than in their white counterparts. ${ }^{21}$

Ultraviolet radiation has been implicated in other ocular diseases. These include skin tumours of the eyelids, squamous carcinoma of the conjunctiva and climatic droplet keratopathy (CDK). The latter condition occurs not only in hot sunny climates but in cold climates where ultraviolet light is reflected from snow. ${ }^{22}$ If pterygium, pinguecula and CDK share the same environmental causative factor, they should co-exist in patients who are exposed to this factor. To study this hypothesis, the incidences of these diseases in two community based external eye disease surveys were reviewed. A number of surveys $^{7,18,23}$ have noted the incidences of these diseases in various communities, but little attention has been paid to the co-existence of one or more of them in the same patient.

\section{Prevalence Surveys}

External eye disease surveys were undertaken in communities in two regions of Southern Africa. The methods and results of the two surveys have been reported previously ${ }^{24,25}$. Briefly, members of the populations were selected by random cluster sampling. Prior to the surveys a census was taken of both the sample populations; during the surveys only the results of those people in the census were recorded. External eye examinations were performed using a Haag-Streit slit-lamp.

\section{Calvinia Survey}

This survey ${ }^{24}$ was undertaken in a small Karoo town, inhabited by people of mixed race. The Karoo is a semi-arid area situated inland at latitude $31.5^{\circ} \mathrm{S}$; the vegetation is sparse revealing a dusty, lightly coloured soil which reflects the sunlight. In total 1,650 people were examined during the survey.

\section{Transkei Survey}

The Transkei is a region of Xhosa speaking Bantu people. The survey ${ }^{25}$ was undertaken in the Kentani and Willowvale districts which are situated close to the coast and are at latitude $32^{\circ} \mathrm{S}$. The terraine is predominantly rolling grassland. During the survey 1,519 people were examined.

Both survey areas are therefore situated at almost the same latitude, and are in summer rainfall areas. Although Transkei has a slighty higher rainfall than Calvinia the monthly global solar radiation levels in the two regions are virtually identical. Pterygium, CDK and pinguecula were seen in both Transkei and Calvinia. An analysis of the association between pterygium, pinguecula and CDK was undertaken.

\section{CDK and Pterygium}

In Calvinia the incidence of CDK in the population increased with age, the rise being more marked in males (Figs. 1a and 2a). The incidence of pterygium also increased with age, although pterygia appeared to be commoner in females than males (Figs. $1 \mathrm{~b}$ and $2 \mathrm{~b}$ ) the difference was not statistically significant. The percentage of the population with both CDK and pterygium is shown (Figs. 1 and 2), the incidence increases with age but both sexes 

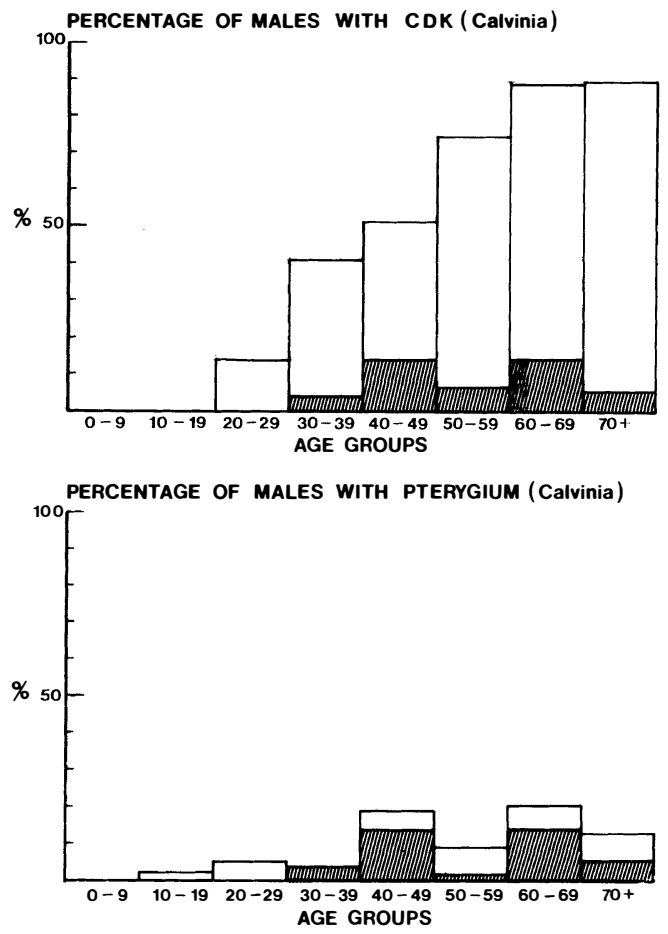

IIIIIIIII/I/Patients with CDK and Pterygium

Fig. 1a and b. The percentage of males in Calvinia with (a) CDK and (b) pterygium. Stippled area indicates subjects with both disorders.

were equally affected. Combining the figures for males and females the observed incidence of the two diseases occurring together in the same patient was not significantly different from the value predicted if the two diseases were unrelated $\left(\chi^{2}: 0.1>p>0.05\right)$.

In Transkei the incidence of CDK was again higher in the older population and in males (Figs. 3a and b). Only seven people were found to have pterygium, these were all females. Four of these women did not have CDK (Fig. 3b) the remaining three had CDK; the numbers are too small to analyse statistically.

\section{Pinguecula and Pterygium}

In Calvinia the incidence of pinguecula increased with age in both males and females, the incidence was higher in the latter (Figs. 4a and 5a). The incidence of pterygium has been commented on above (Figs. $4 \mathrm{~b}$ and $5 \mathrm{~b}$ ); inter- estingly the age of onset of pterygium was earlier than pinguecula in males, the disease first appeared in the 10-19 year age group. The incidence of pterygium and pinguecula occurring together was not statistically different than if the diseases were unrelated $(\mathrm{p}=>0.1)$.

The incidence of pinguecula in Transkei was high in both males and females (Figs. 6a and b). Three of the seven females with pterygium had associated pinguecula; because of the small numbers of patients with pterygium statistical analysis was not performed.

In both Calvinia and Transkei the incidence of CDK followed a similar pattern. The disease commenced in the 20-29 year age group and was commoner in older people. Males were affected more frequently than females; in males older than 70 years the incidence of CDK was 90 per cent and 100 per
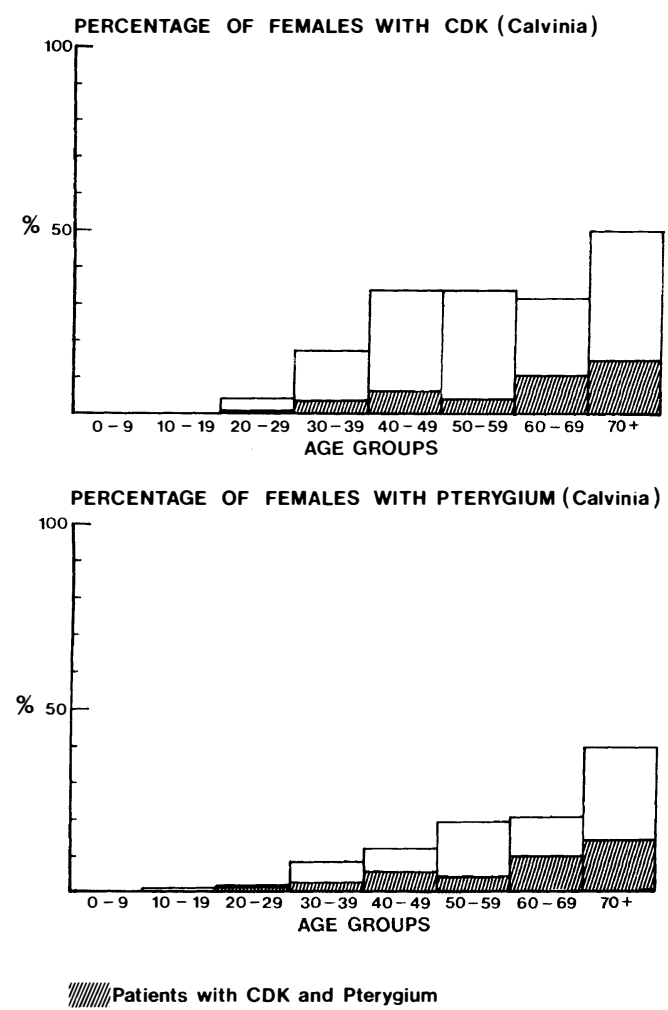

Fig. 2a and b. The percentage of females in Calvinia with (a) CDK and (b) pterygium. Stippled areas indicate subjects with both disorders. 

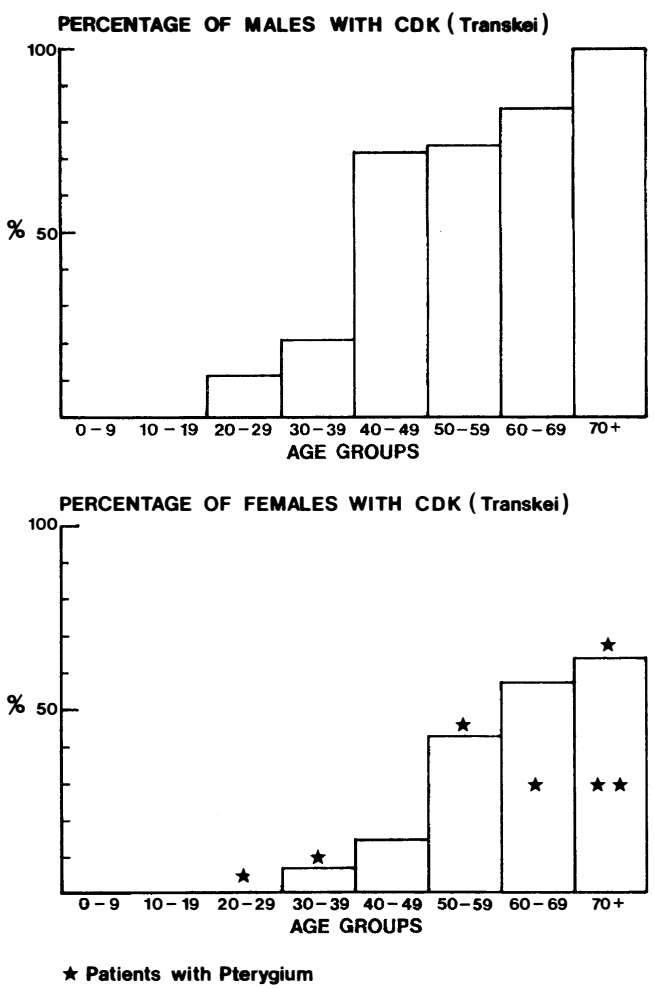

Fig. 3a and b. The percentage of (a) males and $(b)$ females with CDK. Stars indicate subjects with pterygia.

cent in Calvinia and Transkei respectively. In addition the disease became more severe in the older age groups in both regions, causing a significant amount of blindness. CDK is a typical degenerative disorder as both the incidence and severity of the disease increase with age. An environmental aetiology has been suggested: UV radiation is thought to denature plasma proteins as they diffuse through the cornea resulting in their deposition and accumulation. ${ }^{26}$ The distribution of $\mathrm{CDK}$ in the palpebral fissure, initially at the corneal periphery, is consistant with a direct radiation effect, as is the initial superficial location. No relationship has been found between $\mathrm{CDK}$ and latitude or between CDK and UV or total global radiation. ${ }^{12}$ But $\mathrm{CDK}$ was found to be commoner in outdoor workers and the condition almost surely results from environmental exposure. There is strong circumstantial evidence that UV radiation is the causative factor. ${ }^{y, 12}$
The incidence of pinguecula was also age related. In Calvinia females were affected more frequently than males. Whereas in Transkei the incidence was very much higher and there was no significant difference between the sexes. The high incidence of pinguecula in Transkei cannot easily be explained, but other environmental factors may be responsible in particular the high smoke levels within the family dwellings. ${ }^{27}$ Other surveys have found an increased incidence in older age groups and have incriminated exposure to sunlight as the causative factor. ${ }^{18}$

The most marked difference between the two surveys is the dissimilarity in the incidences of pterygium. Only seven people in the Transkei survey had this disorder and all were females: the most likely explanation for this low incidence is that these people possess an inherited resistance to this disorder. Another
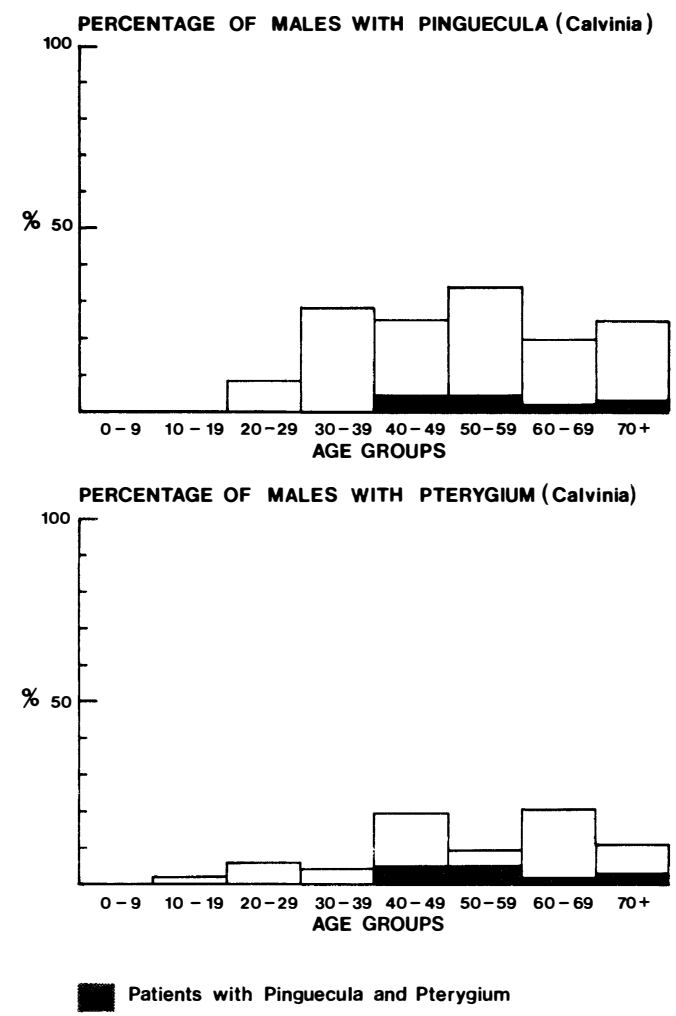

Fig. 4a and b. The percentage of males in Calvinia with $(a)$ pinguecula and (b) pterygium. Stippled areas indicate subjects with both disorders. 

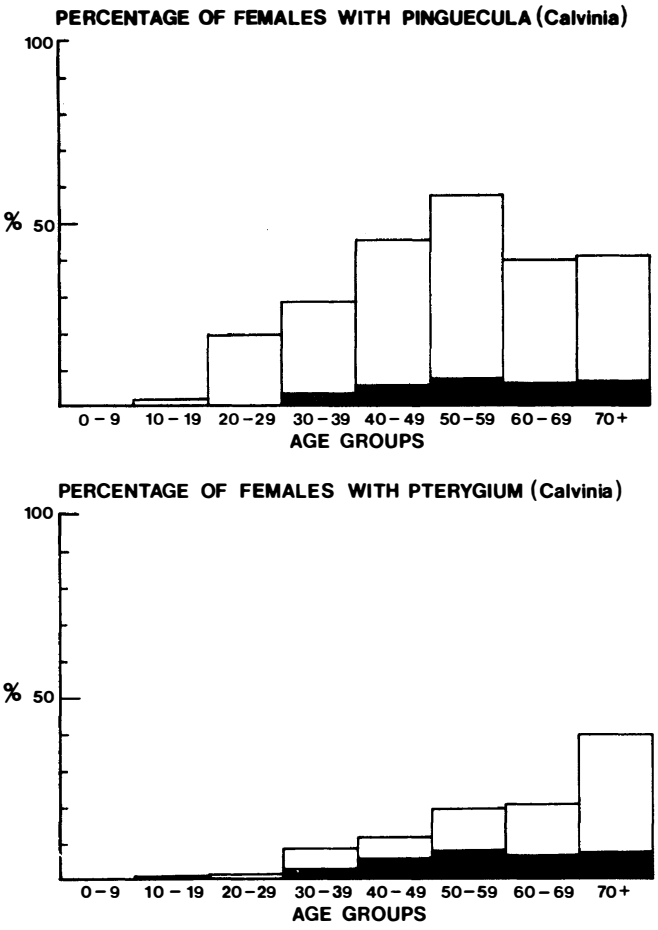

Patients with Pinguecula and Pterygium

Fig. 5a and b. The percentage of females in Calvinia with (a) pinguecula and (b) pterygium. Stippled areas indicate subjects with both disorders.

possible explanation is that the presence of arcus has a protective effect, ${ }^{19}$ while it is true that the incidence of arcus is high it is not present in the younger age groups in whom pterygium first becomes manifest elsewhere.

The obvious difference in the incidences of $\mathrm{CDK}$, pinguecula and pterygium is an indication that these disorders are not closely linked. In Transkei the low incidence of pterygium is in stark contrast to the incidences of CDK and pingueculum. In Calvinia where the incidence of pterygium is higher there was no statistical association between this disorder and either CDK or pinguecula. The pattern of people affected by CDK was similar in both population groups, and from the evidence available it is likely that CDK is related solely to UV exposure over long periods of time. Although UV radiation plays an important role in the aetiology of pterygium and pinguecula there are probably other factors which are necessary to initiate these dis- orders. In the case of pterygium it is possible that chronic inflammation is an essential requisite for development. The figures from Transkei indicate that pinguecula do not necessarily develop into pterygium. The presence of young people in Calvinia with pterygium but no evidence of pinguecula indicate that pterygium can develop independently of the presence of a pinguecula.

\section{Pathogenesis}

Apart from the aetiological factors that initiate pterygium, there is much uncertainty about histological stages that occur in the formation of this disorder. The elastotic changes that occur in the dermis, in pinguecula and in pterygium are similar but the most obvious feature of a pterygium is the increased vascularity. Why new vessels should invade the normally avascular cornea has not been adequately explained. Although many nox-

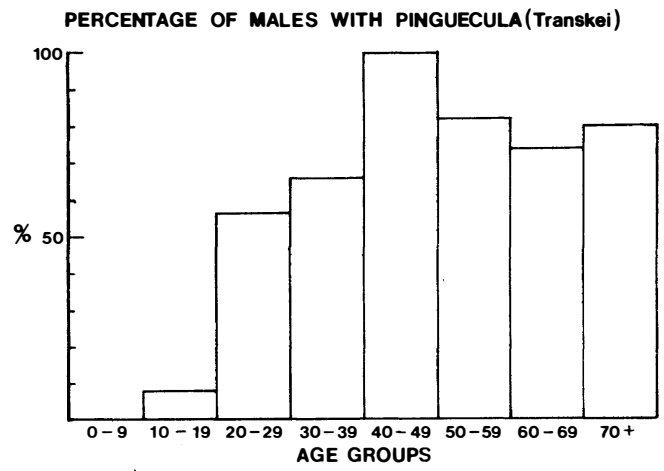

Percentage of females With pinguecula (Transkei)

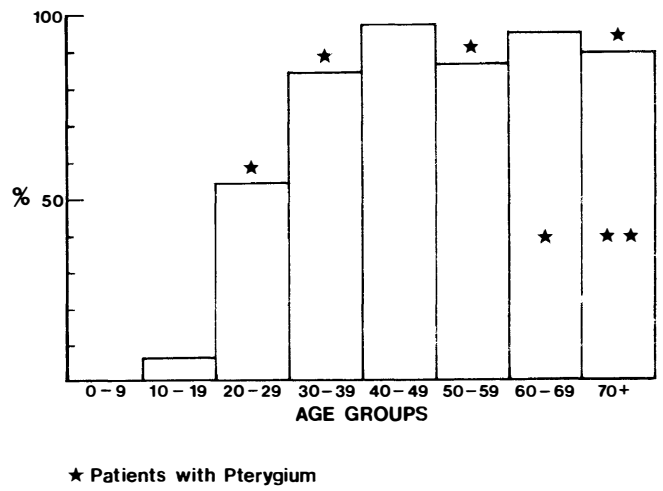

Fig. 6a and b. The percentage of (a) males and (b) females with pinguecula. Stars indicate subjects with pterygia. 
ious stimuli, notably infections such as bacterial keratitis and trachoma or chemical injuries especially from alkali burns, cause neovascularisation, many injuries such as lacerations or acute ultraviolet burns do not. Acute lesions are not usually associated with vascularisation, whereas chronic inflammatory diseases usually are accompanied by new vessel growth.

In their communication on corneal vascularisation. Ashton and $\mathrm{Cook}^{28}$ advance two main theories to explain corneal new vessel formation. Firstly in disease a substance is elaborated in the cornea which stimulates limbal vessels to grow towards the site of its maximal concentrations. The second theory is that the limbal vessels are normally prevented from entering the cornea because of growthinhibiting substances or through the compactness of its tissue: vacularisation would then arise through destruction of the antagonising substance or through a reduction in corneal compactness. Campbell and Michaelson ${ }^{29}$ reported two important findings. They found that following a small focal corneal injury the blood vessels tended to grow toward the lesion within an area resembling an isosceles triangle: a shape reminiscent of most pterygia. They also noted that the induction of corneal vascularisation depended on the proximity of the lesion to the corneoscleral limbus.

Fromer and Klintworth ${ }^{30}$ showed that in most models of corneal vascularisation the new vessel growth was preceded by the arrival of leucocytes. In a later publication the same authors ${ }^{31}$ reported that polymorphs, or in some instances macrophages, were the cell types responsible. Klintworth ${ }^{32}$ suggested that the oedema, reported by $\mathrm{Cogan}^{33}$ to accompany and precede corneal vascularisation, was probably inflammatory in nature. He also suggested that corneal oedema in itself did not stimulate vessel growth but made penetration of the stroma easier ${ }^{32}$ hence corneal oedema in diseases such as Fuch's dystrophy is not invariably associated with neovascularisation. The localisation, depths of stromal involvement, and direction of the vascular invasion from the limbus corresponds extremely well to the pattern of stromal leukocytic infiltration. ${ }^{32}$

Whether a leukocytic infiltration of the cor- nea is responsible for the new vessels seen in pterygium is not known. Wong ${ }^{34}$ hypothesised that a pterygium angiogenesis factor was produced by noninfected inflammation at the junction of the conjunctival blood vessels and Bowman's membrane. Although he suggested that the angiogenesis factor was a chemical resulting from autolysis, it is also possible that associated leukocytes are responsible for the vascularisation. A recent paper ${ }^{35}$ has suggested an immunologic basis for pterygium on the basis that plasma cells, lymphocytes and immunoglobulins were found within it. Immunofluorescent studies revealed the immunoglobulins to be $\mathrm{IgG}$ and $\mathrm{IgE}$. The IgG was found predominantly in the stroma in areas corresponding to the area of plasma cell and lymphocyte infiltration. IgE was distributed in the epithelium, within the stroma and in the region separating these two tissues. Immunofluorescent studies of normal conjunctiva were negative for both $\mathrm{IgG}$ and $\mathrm{IgE}$. Based on these findings the authors suggested an immunologic basis for pterygium. The presence of IgE would indicate a type 1 or immediate type of hypersensitivity which if persistant could lead to chronic inflammation. The antigenic stimulus could come from exogenous irritants such as pollens, dust particles or even viruses. Although attractive, in view of the rather unexpected finding of $\operatorname{IgE}$, the theory does not take cognisance of the strong evidence implicating UV radiation, nor does it explain why pterygium is not found in atopic individuals in higher latitudes.

We have studied 20 consecutive pterygium specimens from patients undergoing surgical removal (unpublished data). Routine stains confirmed the presence of plasma cells and lymphocytes in all the specimens but there was a wide variation in the degree of infiltration. Polymorphs or macrophages were rarely seen. Monoclonal antibody studies indicated that almost all the lymphocytes were $\mathrm{T}$ cells. These cells are responsible for cell mediated immunity and type 4 hypersensitivity reactions in contrast to type 1 allergic rections that are mediated by IgE immunoglobulins. The presence of $\mathrm{T}$ lymphocytes in pterygia as well as $\mathrm{IgG}$ and $\mathrm{IgE}$, may indicate that both humoral and cell mediated hypersensitivity reactions are involved in the pathogenesis of 
pterygium and may be responsible for a chronic intammatory reaction.

The first clinical change seen at the head of a pterygium appears at the level of Bowman's membrane in which small pock like defects occur, collander degeneration. It is tempting to suggest that this is caused by UV radiation. This damage could result in an activation and invasion of fibroblasts from the limbus that attempt to repair the damage. The response may be excessive leading to elastotic material being deposited secondary to elastodysplasia and elastodystrophy: a similar series of events probably occurs in actinic elastosis of the dermis and pinguecula. The increased cellular activity on its own may encourage the ingrowth of blood vessels. However, it has been mentioned that corneal vascularisation is usually preceded by inflammation and leucocytic infiltration. We hypothesise that in susceptible individuals actinic damage causes an alteration in the cornea; this may be aided by external antigens. The damaged tissue is then recognised as foreign and hypersensitivity reactions are mounted resulting in chronic inflammation. Initially a focal conjunctivitis occurs at the corneoscleral limbus ('chronic irritative exposure conjunctivitis') this later develops into a pterygium. ${ }^{14}$ The $\mathrm{T}$ lymphocytes involved in this chronic inflammation liberate lymphokines which are known to induce angiogenesis. ${ }^{36-38}$ The avascularity of the cornea would prevent diffusion of these angiogenic factors and concentrated foci of them would induce neovascularisation in an isosceles pattern. ${ }^{29}$ This theory takes cognisance of the immunological features described and supports the theory of Wong ${ }^{34}$ who suggested that autolysis produces an amino acid mix that acts as an angiogenesis factor. Our theory postulates that damage induces a chronic inflammatory response which in turn is the common final pathway for corneal neovascularisation. Another possible cause for the chronic inflammation that occurs at the limbus involves the formation of dellen at this site secondary to swelling of the adjacent conjunctiva. ${ }^{12}$ Rapid break up of the tear film would be encouraged by high temperatures and evaporation. Again the final common pathway would be an inflammatory cell induced angiogenesis.
In conclusion, we have reviewed the histo-

logical and epidemiological characteristics which suggest that pterygia are caused by chronic ultraviolet exposure. However, there is evidence to suggest that other forms of chronic irritation may play a role in the aetiology of pterygia. The data collected from the two Southern Africa epidemiological surveys indicate that pterygia are not closely linked to other chronic actinic disorders such as pinguecula and CDK. In addition a pinguecula does not appear to be a necessary precursor to pterygium formation. The increased vascularity seen in pterygia, but not pinguecula or $\mathrm{CDK}$, suggests that chronic inflammation (from whatever cause) plays a role in the pathogenesis. The resultant inflammatory oedema, attempt at repair and cellinduced angiogenesis are responsible for the fibrovascular reaction so characteristic of a growing pterygium.

Financial support was provided by the South African Bureau for the Prevention of Blindness and the South African Medical Research Council. The surveys were organised with the help and encouragement of $\mathrm{Mr}$. Sarel van der Walt, Director of the Bureau for the Prevention of Blindness. Dr. R. Bowen provided histological assistance.

\section{References}

${ }^{1}$ Duke-Elder S: Textbook of ophthalmology. St Louis: Mosby, 1954, 7: 570-86.

2 Spencer WH and Zimmerman LE: Conjunctiva. In: Spencer WH, ed. Ophthalmic pathology: an atlas and textbook, Vol 1. Philadelphia: WB Saunders, 1985, 109-228.

${ }^{3}$ Cogan DG, Kubara T, Howard J: The nonelastic nature of pingueculas. Arch Ophthalmol 1959, 61: 388-9.

${ }^{4}$ Hogan $M J$ and Alvarado J: Pterygium and pinguecula: Electron microscopic study. Arch Ophthalmol 1967, 78: 174-86.

${ }^{5}$ Austin P, Jakobiec FA, Iwamoto T: Elastodysplasia and elastodystrophy as the pathologic bases of ocular pterygia and pinguecula. Ophthalmology 1983, 90: $96-109$.

${ }^{6}$ Ledoux-corbusier $M$ and Danis P: Pinguecula and actinic elastosis. J Cut Pathol 1979, 6: 404-13.

${ }^{7}$ Hilgers JHC: Pterygium: its incidence, heredity and etiology. Am J Ophthalmol 1960, 50: 635-44.

${ }^{8}$ Cameron ME: Pterygium throughout the world. Springfield, Ill: Charles C. Thomas, 1965.

${ }^{9}$ Taylor HR: Aetiology of climatic droplet keratopathy and pterygium. Br J Ophthalmol 1980, 64: $154-63$.

${ }^{10}$ Darrell RW and Bachrach CA: Pterygium among veterans. Arch Ophthalmol 1963, 70: 158-69. 
${ }^{11}$ Moran DJ and Hollows FC: Pterygium and ultraviolet radiation: a positive correlation. $\mathrm{Br} J$ Ophthalmol 1984, 68: 343-6.

12 Taylor HR: Climatic droplet keratopathy and pterygium. Aust J Ophthalmol 1981, 9: 199-206.

${ }^{13}$ Fuchs E: Ueber das Pterygium. Albrecht von Graefes Arch Ophthalmol 1892, 38: 1-90.

${ }^{14} \mathrm{Kamel} \mathrm{S}$ : The pterygium: its etiology and treatment. Am J Ophthalmol 1954, 38: 682-8.

${ }^{15}$ Kerkenezov N: A pterygium survey of the far north coast of New South Wales. Trans Ophthalmol Soc Aust 1956, 16: 110-19.

${ }^{16}$ Hubner W: Der Lidspaltenfleck. Arch Augenheilkd 1898, 36: 70-91.

${ }_{17}$ Talbot G: Pterygium. Trans Ophthalmol Soc NZ 1948, 2: 42-5.

${ }^{18}$ Norm M: Spheroid degeneration, keratopathy, pinguecula, and pterygium in Japan (Kyoto). Acta Ophthalmol 1984, 62: 54-60.

${ }^{19} \mathrm{Karai}$ I and Horiguchi S: Pterygium in welders. $\mathrm{Br} \mathrm{J}$ Ophthalmol 1984, 68: 347-9.

${ }^{20}$ Ansari MW, Rahi AHS, Shukla BR: Pseudoelastic nature of pterygium. Br J Ophthalmol 1970, 54: 473-6.

${ }^{21}$ Detels R and Dhir SP: Pterygium: a geographical study. Arch Ophthalmol 1967, 78: 485-91.

${ }^{22}$ Freedman A: Labrador keratopathy. Arch Ophthalmol 1965, 74: 198-202.

${ }^{23}$ Forsius H: 1972, 1974, 1978. Cited by: Norm M. Spheroid degeneration, keratopathy, pinguecula, and pterygium in Japan (Kyoto). Acta Ophthalmol 1984, 62: 54-60.

${ }^{24}$ Hill JC: The prevalence of corneal disease in the coloured community of a Karoo town. S Afr Med J 1985, 67: 723-7.

${ }^{25}$ Hill JC, Maske R, Van der Walt S, Coetzer P: Corneal disease in rural Transkei. S Afr Med J 1989 (In Press).

${ }^{26}$ Johnson GJ and Overall M: Histology of spheroidal degeneration of the cornea in Labrador. $\mathrm{Br} \mathrm{J}$ Ophthalmol 1978, 62: 53-61.

${ }^{27}$ Maske R, Hill JC, Van der Walt S: Smoke related pingueculae in rural Transkei. (Submitted for publication.)

${ }^{28}$ Ashton $\mathrm{N}$ and Cook C: Mechanisms of corneal vascularisation. Br J Ophthalmol 1953, 37: 193-209.

${ }^{29}$ Campbell FW and Michaelson IC: Blood-vessel formation in the cornea. Br J Ophthalmol 1949, 33: 248-55.

${ }^{30}$ Fromer $\mathrm{CH}$ and Klintworth GK: An evaluation of the role of leukocytes in the pathogenesis of experimentally induced corneal vascularisation. II Studies on the effect of leukocyticelimination on corneal vascularisation. Am J Pathol 1975, 81: 531-44.

${ }^{31}$ Fromer $\mathrm{CH}$ and Klintworth GK: An evaluation of the role of leukocytes in the pathogenesis of experimentally induced corneal vascularisation. III Studies related to the vasoproliferative capability of polymorphonuclear leukocytes and lymphocytes. Am J Pathol 1976, 82: 157-70.

32 Klintworth GK: The cornea: structure and macromolecules in health and disease. Am J Pathol 1977, 89: 719-808.

${ }^{33}$ Cogan DG: Vascularisation of the cornea. Its experimental induction and a new theory of its pathogenesis. Arch Ophthalmol 1949, 41: 406-16.

${ }^{34}$ Wong WW: A hypothesis on the pathogenesis of pterygiums. Ann Ophthalmol 1978, 10: 303-8.

${ }_{35}$ Pinkerton OD, Hokama Y, Shigemura LA: Immunologic basis for the pathogenesis of pterygium. Am J Ophthalmol 1984, 98: 225-8.

${ }^{36}$ Nishioka K and Katayama I: Angiogenic activity in culture supernatant of antigen-stimulated lymph node cells. J Pathol 1978, 126: 63-9.

${ }^{37}$ Auerbach R and Sidky YA: Nature of the stimulus leading to lymphocyte-induced angiogenesis. $J$ Immunol 1979, 123: 751-4.

${ }^{38}$ Ben Ezra D: Neovasculogenesis. Triggering factors and possible mechanisms. Surv Ophthalmol 1979, 24: $167-76$. 